\title{
Effect of gibberellin on fruit preservation and quality of Zizyphus Jujuba
}

\section{'Zhanshanmizao'}

\author{
Yuyang Zhang ${ }^{1, \mathrm{a}}$, Huifen Zhang ${ }^{1, b^{*}}$, Yan Zhou ${ }^{1, \mathrm{c}}$ and Jie Zhou ${ }^{1, \mathrm{~d}}$ \\ ${ }^{1}$ College of Horticulture, Sichuan Agricultural University, Chengdu, Sichuan, China \\ a1418273727@qq.com, b1042335395@qq.com, ㄹhouyan6213500@qq.com, d493137598@qq.com \\ *Corresponding author
}

Keywords: Zizyphus Jujuba 'Zhanshanmizao'; gibberellin; fruit retention; guarantee the quality

Abstract. The effects of different concentrations of gibberellin $\left(\mathrm{GA}_{3}\right)$ on fruit preservation and quality and the physiological mechanism of action were studied. The results showed that the soluble sugar content of Zizyphus Jujuba 'Zhanshanmizao' was on the rise from young fruit stage to mature stage and fluctuated between the middle of July and the middle of August. GA 3 had good fruit retention effect. The content of soluble protein was high at the beginning and decreased gradually with the increase of time. The variation of titrable acid content showed a decreasing trend. Vitamin $\mathrm{C}(\mathrm{Vc})$ content fluctuated greatly. Generally speaking, each treatment had no obvious effect on fruit development and quality.

\section{Introduction}

The flowers of jujube trees is plenty, and the flowering period is long. At the same time, the trees consumes nutrition much. Fruit drop rate of Zizyphus Jujuba 'Zhanshanmizao' is high. The fruit setting rate accounts for only $1 \%$ 2\% of the total amounts of flowers in general, which limits the output per unit area of them. Plant growth regulator has been widely used in fruit production, which has become one of the essential measures of high yield and high quality [1,2,3,4,5]. Therefore, it is quite significant to study the effect of plant growth regulator on fruit setting, fruit development and the quality of jujube trees in order to improve its yield and promote its industrial development.

The jujube trees were treated by spraying different concentrations of $\mathrm{GA}_{3}$ at full-bloom stage. While analysing the processing and the results about dynamic growth and the change of fruit inclusions, we can find out plant growth regulator is useful to improve its yield and fruit quality.

\section{Materials and Methods}

Materials. The experiment base is located in jujube experimental garden, Yongxin Town, Yonglian Village, Santai County, Mianyang City. The trees that selected as test species showed driving life force. And they were basically the same size.

Experimental Design. On May 17 th, the trees were at full-bloom stage. Jujube flower numbers were at $25 \%$ to $75 \%$. Chose windless weather before 9 a.m. or after 5 p.m. and the temperature was low when we were spraying different concentrations of gibberellin $\left(\mathrm{GA}_{3}\right)$. The concentration of $\mathrm{GA}_{3}$ was set as $10 \mathrm{mg} / \mathrm{L}, 20 \mathrm{mg} / \mathrm{L}, 30 \mathrm{mg} / \mathrm{L}$, and $40 \mathrm{mg} / \mathrm{L}$, with water as the control (CK).

The experiment adopted the randomized block method. Each tree was randomly selected 4 fruiting groups in 4 different directions such as east, south, west and north. Then listed and ranked 
them correctly. Each zone had 3 trees. Repeated each treatment three times. The other management measures were same as those local trees. The hand cranking compression sprayer was used to spray each group to an adequate degree. The $\mathrm{GA}_{3}$ was sprayed uniformly on the surface of leaves and flowers. Neighbouring plants were separated by plastic films before spraying.

Statistical Analyses. Fruit Abscission Rate $=$ the total number of flowers - (flower number + fruit set number)/total number of flowers $x 100 \%$.

From seedling stage to the maturation of jujube fruits, $250 \mathrm{~g}$ fruits were taken on the upper and middle fruiting branches (shedding shoot of jujube) of each treatment group per 14 15d. Preserved and brought fruits by using low temperature incubators back to the laboratory. Measured the fruit weight, fruit diameter and soluble sugar, titratable acid and vitamin $\mathrm{C}(\mathrm{Vc})$. Compared the influence of different treatments on growth and fruit quality. The vertical and horizontal diameter of the fruit was measured by the vernier caliper. Soluble sugar content was determined by Anthrone Colorimetry [6]. Titrable acid content was determined by acid alkali titration method [6]. Vitamin C content was determined by 2, 6-Dichlorophenolindophenol Na salt titrationhop [6].

\section{Results and Discussion}

The Fruit Fresh Weight. In terms of the overall fresh weight growth trend of the jujube, there was little difference between each treatment and the control. The whole process was consistent. Fresh weight of Zizyphus Jujuba 'Zhanshanmizao' increased from $0.2568 \mathrm{~g}$ at young fruit stage to about $4.0184 \mathrm{~g}$ in the end (Fig. 1).

Fruit Diameter. The fruit longitudinal and traverse diameter growth was rapid. The jujube diameter rose abruptly, and it reached its growth peak. There was a slow growing trend when jujube trees had fruit ripening. According to the whole growth trend of fruit diameter, there was no obvious difference between treatment (Fig. 2).

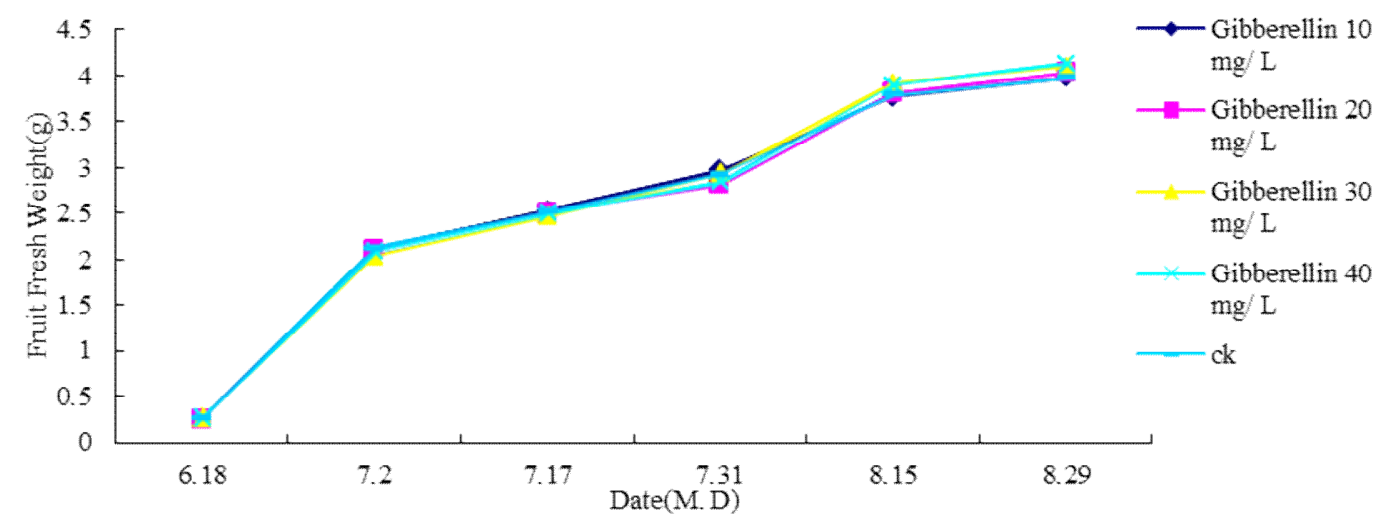

Fig. 1 The fruit fresh weight of jujube trees with different concentrations of $\mathrm{GA}_{3}$

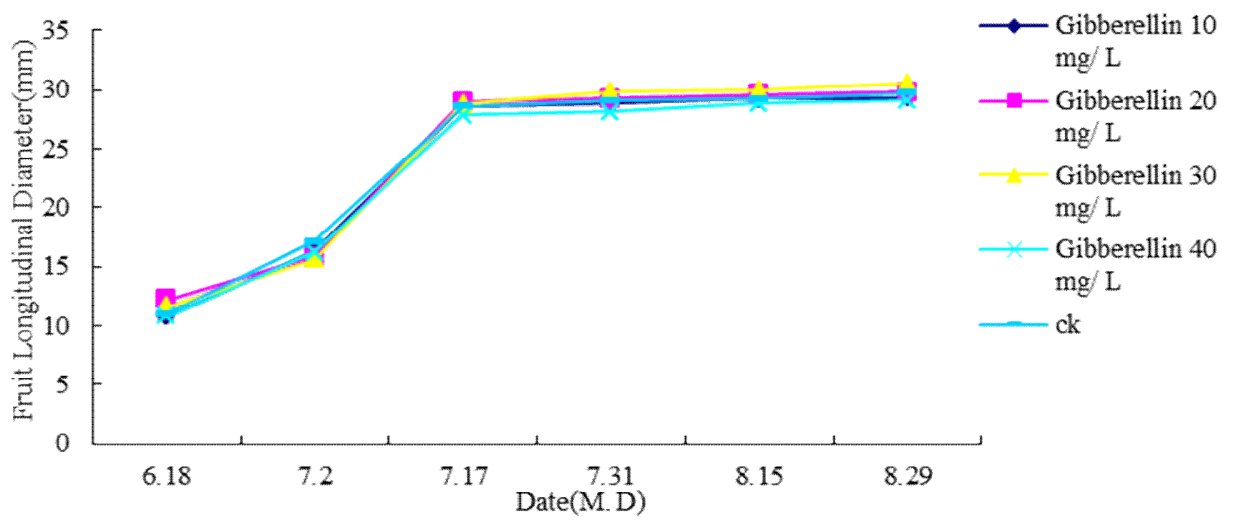

Fig. 2 Fruit longitudinal diameter of jujube trees with different concentrations of $\mathrm{GA}_{3}$ 


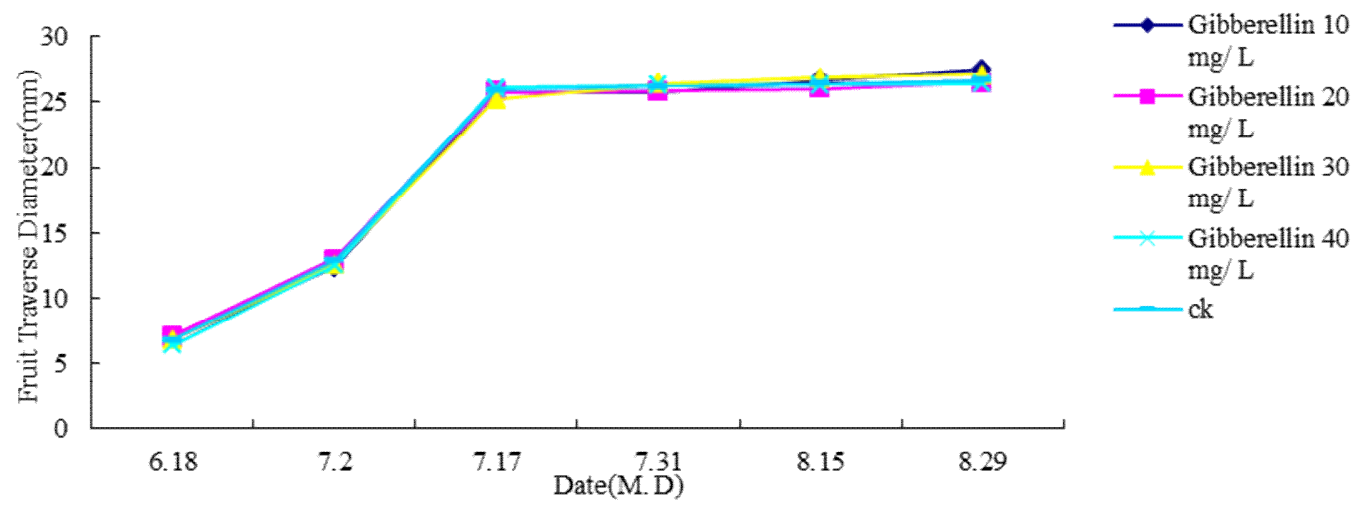

Fig. 3 Fruit traverse diameter of jujube trees with different concentrations of $\mathrm{GA}_{3}$

Fruit Drop Rate. The phenomenon of falling fruit was common and the rate of falling fruit was increasing. After the first fruit drop peak in early July, the rate increased slowly. The second peak occurred in mid-August, but it was much lower than the first one. In terms of the whole fruiting trend, there was no significant difference between the treatments except $\mathrm{GA}_{3} 20 \mathrm{mg} / \mathrm{L}$ treatment which was before the middle of August. From the middle of August to the end of August, the fruit ripening rate was consistent (Fig. 4).

Soluble Sugar. The soluble sugar content in Zizyphus Jujuba 'Zhanshanmizao' was on the rise from young fruit stage to its maturation, and the changing trend between treatments and controls was consistent. However, the difference was large (Fig. 5).

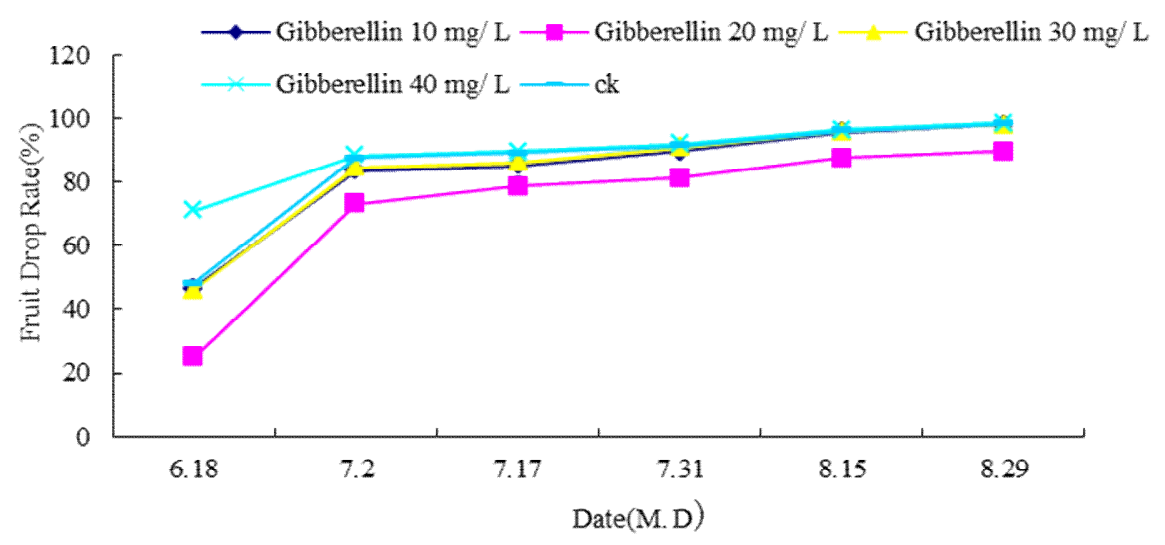

Fig. 4 Fruit drop rate of jujube trees with different concentrations of $\mathrm{GA}_{3}$

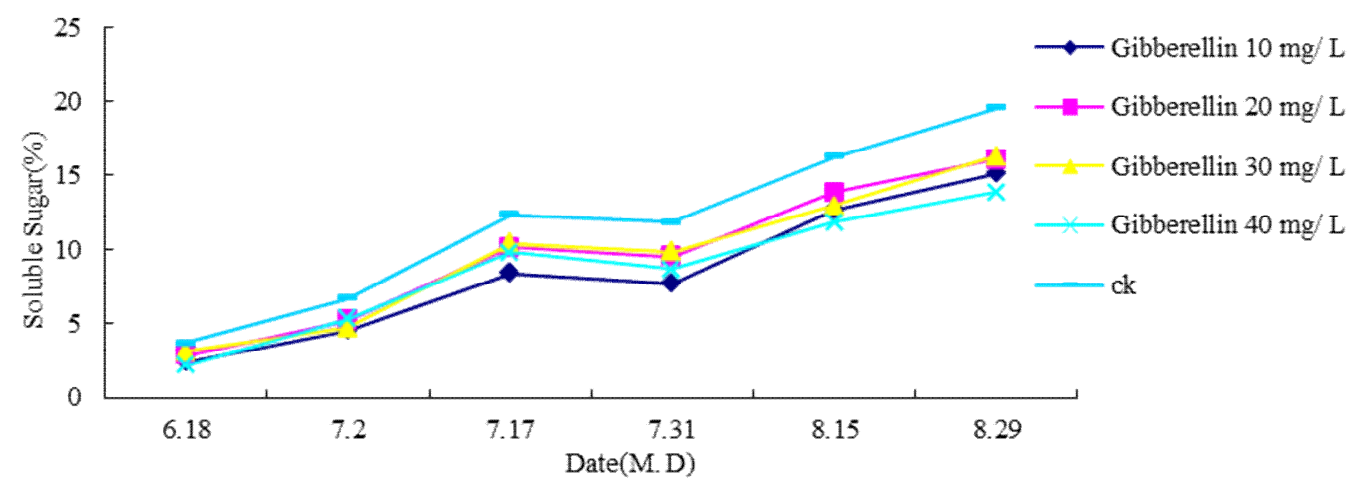

Fig. 5 Soluble sugar of jujube trees with different concentrations of $\mathrm{GA}_{3}$ 
Titrable Acid and Vc. The titrable acid content of trees was generally decreasing, with only the fluctuation between the early August and the late August fruit ripening period. From the middle of June to early July, it fell sharply. And in early July, after slow decline until the end of that month, titrable acid of early August began to rise slightly. In the middle of August and then it began to decline until the fruit ripened. The titrable acid content at the beginning of each treatment and control was evidently different from CK $1.09 \%, \mathrm{GA}_{3} 20 \mathrm{mg} / \mathrm{L} 1.38 \%$ and $\mathrm{GA}_{3} 30 \mathrm{mg} / \mathrm{L} 0.89 \%$ (Fig. 6). There is no significant difference of Vc between treatments and controls (Fig. 7).

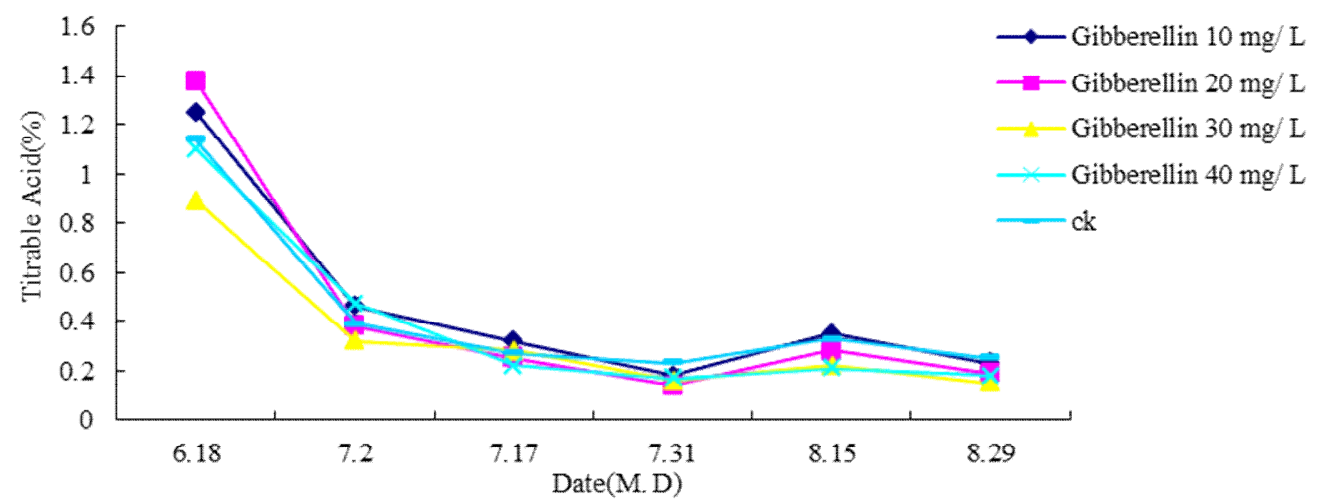

Fig. 6 Titrable acid of jujube trees with different concentrations of $\mathrm{GA}_{3}$

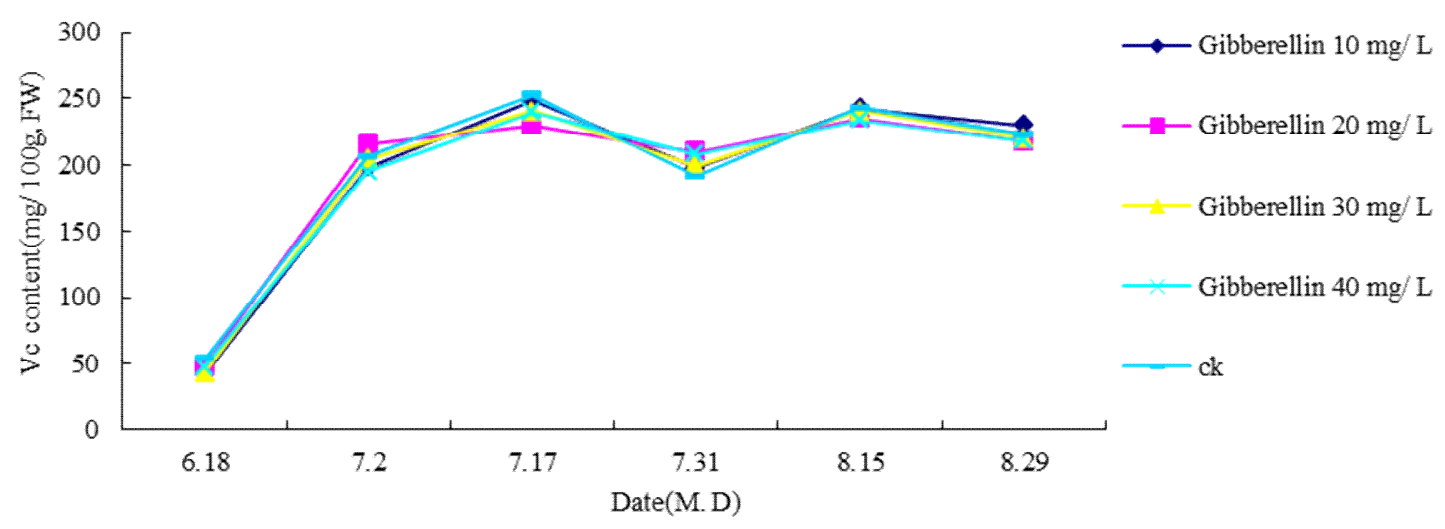

Fig. 7 Vc content of jujube trees with different concentrations of $\mathrm{GA}_{3}$

\section{Conclusions}

This experiment showed that the application of $\mathrm{GA}_{3}$ during the blooming period of jujube trees had little effect on fruit fresh weight, longitudinal diameter and traverse diameter of Zizyphus Jujuba 'Zhanshanmizao', with only $\mathrm{GA}_{3} 40 \mathrm{mg} / \mathrm{L} 4.1246 \mathrm{~g}$ of fresh weight, slightly higher than CK $3.9828 \mathrm{~g}$.

In terms of quality, $\mathrm{GA}_{3}$ sprayed during blooming period had no significant effect on titrable acid and Vc content. Only the soluble sugar content was obviously affected. Soluble sugar content in the samples treated with $\mathrm{GA}_{3}$ was much lower than that of the control group. Through this experiment, it can be clear that whether specific formula of $\mathrm{GA}_{3}$ injection to help jujube trees have a low fruit drop rate or improve the quality of the jujube has yet to be further studied.

\section{Acknowledgements}

This work was financially supported by the double subject construction plan of Sichuan Agricultural University and Special action plan project of science and technology rich people and 
strong county of Sichuan Province "integration and demonstration of key technologies for industrialized development of Zizyphus jujube 'Zhanshangmizao'of Santai County”.

\section{References}

[1] C.J. Li: Plant Physiology Communications Vol. 6 (1995), p. 401.

[2] H.Q. Zhang: Modern Agricultural Science and Technology Vol. 5 (2010), p. 107.

[3] C.D. Li: Beijing NongYe Vol. 34 (2009), p. 23.

[4] T. Wu, Z.X. Wu, Q.G. Li: Northwest Horticulture Vol. 3 (2010), p. 11.

[5] Q.H. Ma, J.R. Xu, G.X. Wang: Chinese Agriculture Science Bulletin Vol. 26 (2010), p. 234.

[6] H.S. Li: The Principle and Technology of Plant Physiology and Biochemistry Experiment (Higher Education Press, Beijing 2000). 